\title{
Mapping Of Mosquito Distribution And Influencing Factors From Salem District, Tamilnadu Using Geographical Information System (Gis)
}

R. Villavan ${ }^{1}$, Pari Madhiyazhagan ${ }^{2 *}$, Arjunan Naresh kumar ${ }^{3}$, N. Kanagaraju ${ }^{4}$

${ }^{1}$ Department of Biological Science, Gnanamani College of Education, Namakkal, Tamilnadu 637018, India.

${ }^{2}$ Department of Zoology, J. K. K. Nataraja College of Arts and Science, Komarapalayam-638 183, Tamilandu, India.

${ }^{3}$ Department of Zoology, Periyar University, Salem-636011, Tamil Nadu, India.

${ }^{4}$ Department of Zoology, Kandaswami Kandar's College, Namakkal-638 182, Tamilandu, India.

E-mail address:

*Corresponding author. Tel.: +919445417220.

*E-mail address: madhiyazhaganpari@yahoo.com

\section{Abstract}


In India, Mosquito borne diseases constitute a major public health problem in the list of communicable diseases. The most important are malaria, dengue fever, chikungunya fever. Some environmental factors greatly influence the vector prevalence. One of the important components of vector-borne disease control programme is to impart awareness about mosquito bite prevention in the general community. Therefore, the urgent need a technology to give awareness to public about present situation of mosquito-borne disease epidemic prevalence in the country. Geographic information system (GIS) is a powerful tool to analyse the distribution of mosquitoes and their relationship to different environmental factors, and can substantially improve our ability to quantify the impacts of demographic, climatic and ecological changes in vector distribution. The influence factor of vector prevalence was collected from particular departments and direct inspection of field survey. The collected data was interpreted using ArcGIS (version 10.0) for thematic map preparation. Result of the study obtained the environmental factors such as human population, percentage of education greatly influence the mosquito breeding sites. The output is laymen friendly model and reaches the public with more interest. This study also stresses the importance of mosquito control measures.

Keywords: GIS, breeding sites, mosquito-borne diseases, ArcGIS, environmental factors

\section{Introduction}


In recent decades, the incidence of mosquito-borne viral infections has grown dramatically. For example, according to the World Health Organization (WHO), more than 2.5 billion people over $40 \%$ of the world's population are estimated to be at risk from DENV alone. A recent study has evaluated the incidence of dengue infections to be around 390 million worldwide every year, of which 96 million manifests [1]. According to the National Vector Borne Diseases Control Programme (NVBDCP), the number of cases in India has escalated steadily, from 3306 in 2001 to 50222 in 2012; deaths have risen from 53 in 2001 to 242 in 2012 [2]. Moreover, mosquito-borne virus infections are continuously expanding their geographical range into new areas. The spread of infections from Africa and Asia to other continents is thought to be due to extensive travelling, trade, population growth in high-risk areas, globalization of vectors, urbanization, climatic change, as well as virus genome evolution [3].

Vector control program in developing countries like India is difficult because of lacking in awareness of the diseases transmitted through mosquitoes. The development of mosquitoes resistant to synthetic chemicals, increase in human population which lead to an increase in hosts for mosquitoes, global warming and other demographic conditions are the main reasons for making vector control a challenging issue [4]. Mosquito not only transmit annoyance and become cause of concern for human beings. Mosquito have got highly diversified breeding habitats and poses a challenging task for mosquito control programme. Potential larval habitats of the mosquito can be identified by using remote sensing and geographic information system (GIS) analysis [5].

Geographic information systems (GIS) are computerized systems capable of integrating, displaying and analysing large quantities of spatial data [6]. A GIS is a powerful tool for elucidating spatial patterns and processes. In addition, GIS is able to link spatial and non-spatial data, allowing for a wide range of display and analysis capabilities. GIS has applications in numerous fields of study, including marketing, agriculture, forestry, animal ecology, transportation planning and public health [7]. Applications in public health include the estimation of spatial variation of disease, determination of risk factors of disease, and improved delivery of health services (8,9 and 6). GIS owing to its inherent ability to manage both spatial and non spatial information, provides an excellent framework for disease management. 
In recent years, vector-borne diseases (VBD) have emerged as a serious public health problem in most of the countries including India. Geographical Information System (GIS) is one of the best preventive methods to control the vector borne diseases. Most of the Developed countries are applying this system to form their own policy levels to mitigate the mosquito problem. In India, applying GIS in health sector has just begun. In this context geographic information system (GIS) is helpful in epidemiological settings: for data collection, management, analysis, etc. Benefits of using remote sensing in the identification of mosquito breeding habitats were reported by many researchers [10-15]. Potential larval habitats of the mosquito Culex tarsalis, implicated as a primary vector of West Nile virus in Wyoming, were identified using integrated remote sensing and GIS analyses [16].

The GIS software is available at low cost price for research and education purpose in India. A set of spatial analysis (Kriging, Co-Kriging, Universal Kriging, Block Kriging, Buffering, Map overlay analysis, Fussy analysis, K-means analysis, interpolations, etc) using the GIS Platform namely ARC Info/ARC View, Map Info, Map Maker, EPIMAP, Pop Map, Surfer, Atlas GIS, Geo Statistics+, IDRSI, Geographical Analysis Support System (GRASS), is available to assess the mosquitogenic conditions, mapping the vector habitats, vector abundance, larvae and adult density with more than 90 per cent accuracy [17].

Based on the scientific information the goal of this study was to use low cost GIS in identifying the areas for delineating the mosquito breeding surface areas and to study the mosquitogenic conditions in and around Salem district landscape at different climatic regions. The ability to predict the mosquito vectors will greatly enhance the efficacy of control efforts and will substantially reduce costs of control program with efficient targeting of high-risk areas.

\section{Materials and methods}

Study area 
The study area Salem District is a district of Tamil Nadu state in southern India. Salem is the district headquarters and other major towns in the district include Mettur, Edappadi, Yercaud, Omalur and Attur. Salem is located at $11.669437^{\circ} \mathrm{N} 78.140865^{\circ}$ E. As of 2011 , the district had a population of 3,482,056 with a sex-ratio of 954 females for every 1,000 males. The mean minimum and maximum temperatures during summer and winter vary between $13^{\circ} \mathrm{C}$ to $39^{\circ} \mathrm{C}$.

Yercaud is a hill station in Salem District, in Tamil Nadu, India. It is located in the Shevaroys range of hills in the Eastern Ghats; it is situated at an altitude of 1515 meters (4970 ft) above sea level. Yercaud is located at $11.7794^{\circ} \mathrm{N}, 78.2034^{\circ} \mathrm{E}$. The total extent of Yercaud Taluk is $382.67 \mathrm{~km}^{2}$, including Reserve Forest. The climate of Yercaud is moderate. Winters are fairly mild, starting in September and ending in December. During winter, the hills are covered in mist. Winters range from $12{ }^{\circ} \mathrm{C}$ to $24{ }^{\circ} \mathrm{C}$, and summers from $16{ }^{\circ} \mathrm{C}$ to $30^{\circ} \mathrm{C}$. Rainfall is $1500-$ $2000 \mathrm{~mm}$. Yercaud has population app. 40,000 people during the 2001 census period. Scheduled Tribal population of Yercaud is 24,449 people; the total density of the population is 102 people per $\mathrm{km}^{2}$. Yercaud Taluk consist 64 revenue villages and we have selected 9 revenue villages for this study namely Yercaud, Muluvi, Kombu Thukki, Nagalur, Manjakuttai, Asambur, Kiliyur, Sengadu and Gundur, respectively.

The 9 revenue village has a history of mosquito-borne disease. Each village was considered a single study plot and was visited on several occasions for data collection purposes in collaboration with the Salem District Public Health Department. The boundaries of each village/study plot were determined using the Global Positioning System (GPS). Each site was geo-referenced, its size and the presence of mosquito larvae ascertained, and data entered into a dBase/DBF files of ArcGIS. Pictorial analysis of variations in mosquito distribution was made using serial editing techniques. The parameters characterized according to this process were evaluated using real-time imagery and considered for inclusion as classification variables in a descriptive model of mosquito distribution.

\section{Classification of variables}


Demographic factors such as nature of the place, human population, percentage of education (percentage of people reached their high school level), mosquito density and distribution, species distribution were collected. In our view, each of these variables may be related to the creation and availability of mosquito species and disease. To test this hypothesis for human population density, we evaluated the relationship between the numbers of humans in a study plot and the availability of mosquito species and mosquito-borne diseases.

Land use factors facilitate geographic differentiation of study plots on the basis of variables associated with (human) occupation and the topography and physiography of the land. The study area was classified as agricultural, industrial, or agro-industrial depending on geographical attributes that included land use, arability, the number and type(s) of industries, and the proportion of the human population engaged in each type of industry. Developmental sites of mosquito larvae were taken in account are artificial water containers, and storm water and sewage systems.

Biological factors include some of the quantitative and qualitative attributes of natural mosquito populations that have been determined by human observation and measurement. The simplest of these comprises knowledge of mosquito presence/absence and population density. When larvae were present in a habitat, their density was assessed by capturing those at the water surface in a $350 \mu$-mesh hand-held dip net. The number of samples taken using this technique depended on the surface area of the habitat and ranged between 5 and 60 per habitat (no two samples of larvae were taken from the same location in a habitat). Mosquito larvae were collected in July (when mosquito populations in the Salem District are at their highest level of the year) from mosquito sites using a $350 \mu$-mesh hand-held dip net. The collected larvae were placed in plastic containers with water from the collection site. The containers were closed, placed in a cooler, and returned to the laboratory where some of the larvae were preserved in $80 \%$ ethanol (in $\mathrm{H}_{2} \mathrm{O}$ ) for species identification.

\section{Data analysis}


Feature class data (collection of geographic features that allows homogeneous features to be grouped into a single unit for data storage purposes) for human population-related parameters were acquired from records maintained by the Department of Public Health, Salem District. Environmental data were obtained from the Indian Meteorological Department in Salem. Biological data were acquired by direct observation in field sites using the methods and techniques described above. Geo-referencing of field coordinates with a Salem District, Revenue Village boundary map (purchased from the Department of Survey and Land Records, Salem, Tamil Nadu, India) was performed using ArcMap (Map 1). Spatial analyses were made using ArcGIS (10.0).

\section{Results and Discussion}

Increasing temperatures contribute to a pole ward migration or expansion of the ranges of many organisms [18]. Average annual temperatures have been modeled to increase by up to 4.5 degrees Celsius 2100. Additionally, winter minimum temperatures may increase by up to 2.4 degrees Celsius in that same window [19]. This will likely result in an increased amount of new pest and disease species, as the ranges of many pests and diseases have historically been limited by cold winter minimums. Increasing temperatures also allow for higher rates of growth and reproduction in insect herbivores [20].

Mosquitoes breed faster when temperatures are high. Low temperatures and low humidity cause slow breeding and higher mortality rates. When the temperature drops, mosquitoes are less prone to transmit disease because, in cooler weather, they switch from a blood diet to sugar from plants to provide energy for winter survival. Both dry and wet weather can benefit the infectious mosquito population. Dry spells can help lengthen the mosquito's life cycle, allowing time for diseases to multiply in the infected body and move to the salivary glands. When it's dry, mosquitoes retreat to cool, damp areas to wait for rain. In that type of hibernation, any infection in their saliva becomes more powerful. After rain, puddles and standing water provide ideal locations for breeding more mosquitoes. This statement also agreed with Naresh kumar et al. [21]. Temperature is a key factor in vector-borne pathogen transmission. It can significantly 
affect insect behavior and physiology [22,23] including the extrinsic incubation period of vectorborne pathogens [24].

Map 2 shows the analysis of larval density and mosquito breeding sites. Highest larval density (5.8/dip) recorded in two distribution patterns of mosquito breeding sites (18106-21786, 21787-35368 number of breeding sites/Sq. Km.) out of five and the lowest larval density (2/dip) recorded in one distribution pattern of mosquito breeding sites (1763 number of breeding sites/Sq. Km.) and moderate larval density (2.1-4.8/dip) recorded in two distribution patterns mosquito breeding sites (1764-18105, 18106-21786 number of breeding sites/Sq. Km.) (Table 1). Based on the immature mosquitoes, the study area larval density high to low was represented light colour to dark colour, respectively. Nearly the same results were obtained from the study of [25]. Wilson et al. [26] reported that the major breeding sources observed were plastic drums $34(6.69 \%)$ followed by cement tanks 38 (6.28\%), plastic containers 29 (4.43\%), aluminium utensils $32(3.14 \%)$, tires $3(2.38 \%)$, grinding stones $5(2.34 \%)$, flower pots $3(2.29 \%)$, plastic buckets $5(1.91 \%)$ and iron drums 1 (0.54\%). Similar studies have also been conducted in Tiruchirappalli and Virudhunagar districts of Tamil Nadu, India [27]. Different sampling efficiency among different instars of Culex tritaeniorhynchus by the conventional dipping method was reported by Wada and Mogi [28]. Shogaki and Makiya [29] stated that the bias in sampling efficiency in immature stages of Culex pipiens pollens among the developing stages might be due to differences in vertical distribution of different instars.

Some of the semi agricultural plots recorded moderate and increased number of breeding sites. Water standing on fields for excessive periods of time reduces crop yields, encourages the growth of weeds, presents an unhealthy environment for livestock, and may decrease soil quality, in addition to producing mosquitoes [30]. Barbara Matthys et al. [31] reported that the highest Anopheles larval productivity was observed in rice paddies, agricultural trenches between vegetable patches, and irrigation wells. An indirect link could be established between the occurrence of productive Anopheles breeding sites and agricultural land use through specific man-made habitats, in particular agricultural trenches, irrigation wells, and rice paddies. In this present study also agree with above statement the agricultural area also one of the highest mosquito breeding sites have been found at the salem district. Recently Naresh kumar et al. 
[32,4] was studied GIS-based mapping system for distribution of Culex mosquitoes in the Coimbatore District, Tamil Nadu, India and also he concentrated anopheles distribution areas using GIS technology.

Population density of the study area is shown in map 3. Population density was classified into 5 categories using natural breaks data classification technique. Differentiation of the classes is shown by a range of colours. Population range in the study area was between 1860 to 22921/Sq. Km. Yercaud a industrial villages recorded the lowest population of 1860/Sq. Km. Nagalur, Asambur, Kiliyur and Sengadu recorded population range between 9682 to 12141/Sq. Km. Muluvi recorded population range between 9682 to 12141/Sq. Km. Kombu Thukki recorded population range between 12142 to 17643/Sq. Km. Manjakuttai and Gundur recorded the highest population range between 17644 to 22921/Sq. Km. The thematic map clearly states that the number of breeding sites increases with proportion to the population. Highest number of mosquito breeding sites was recorded in the regions with high population.

Map 4 illustrates the comparative analysis of mosquito breeding sites with percentage of population aware of mosquitoes in the study area. The distribution pattern shows that the lowest to highest number of breeding sites recorded in regions with $66 \%$ to $95 \%$ of population aware of mosquitoes. Moderate number of breeding sites recorded in regions with $60 \%$ to 65 and lesser population aware of mosquitoes.

Generally the proportion of pests directly depends on the host density. Similarly, proportion of mosquito density depends on the human population due to the reason of mosquitoes are attracted by perspiration, warmth, body odor, carbon dioxide, and light. If the water stagnates, there is a greater chance for mosquitoes. There is indeed a clear overlap among the kairomones to which both mosquito species respond: carbon dioxide $\left(\mathrm{CO}_{2}\right)$, ammonia, lactic acid, and other aliphatic carboxylic acids play a role in the host-seeking process of both species [33]. With the exception of $\mathrm{CO}_{2}$, these compounds are present on the human skin and in human sweat [34]. Men have been found to be more attractive to mosquitoes than women [35] whereas An. gambiae did not discriminate between human individuals based on gender [36]. 
Number of breeding sites based on percentage of education in the study area is pictured and presented in map 5. Regions like Gundur and Kombu Thukki with highest education rate (76\% to 79) reported both less and moderate number of breeding sites. Study plots Yercaud and Nagalur exhibiting $62 \%$ to $63 \%$ of education reported very less, less and moderate number of breeding sites; regions like Kiliyur and Sengadu with $64 \%$ to $68 \%$ of education reported moderate number of breeding sites; regions Asambur and Muluvi with $69 \%$ to $70 \%$ of education reported moderate and high number of breeding sites; region Manjakuttai with $71 \%$ to $75 \%$ of education reported moderate and high number of breeding sites.

The present study the thematic map shows of the study almost $80 \%$ of study participants were using one or other personal protective measures against mosquito bite. The commercial product like coil, repellent and mat were used more among literate households compared to illiterate families whereas mosquito net use was almost same among literate and illiterate families. Earlier Sharma et al. [37] reported that majority of Bastat district of Madhya Pradesh did not know about mosquito breeding places. Pravin et al. [38] reported that $91.50 \%$ of the study participants had knowledge about breeding places of mosquito. $22.29 \%$ of study population still had myths that garbage was the breeding place for mosquito. Only $33.72 \%$ of the study population knew that dengue, chikungunya was transmitted by mosquito.

The study plot exhibits a number of mosquito species coming under the four genera, Aedes, Culex, Anopheles and Armigeres. Distribution of Aedes spp, Culex spp, Anopheles spp in the study area is given in map 6. Eight spp. of Anopheles namely, Anopheles (Anopheles) nilgiricus Christophers. (An.N), Anopheles(Cellia) culicifacies . Giles. (An.C), Anopheles(Cellia) elegans (James). (An.E), Anopheles(Cellia) pallidus Theobald. (An.P), Anopheles(Cellia) stephensi Liston. (An.St), Anopheles(Cellia) subpictus Grassi. (An.Su), Anopheles(Cellia) varuna Iyengar. (An.V), Anopheles(Cellia) willmori (James). (An.W) were recorded in the study area. Four species of Aedes were recorded namely, Aedes (Aedimorphus) vittatus (Bigot) (Ae.V), Aedes (Stegomyia) albopictus (Skuse) (Ae.Al), Aedes (Stegomyia) aegypti (Linnaeus) (Ae.Ae), Aedes (Aedimorphus) pipersalatus (Giles) (Ae.P) and Seven Culex spp. in the study plot is mapped out Culex (Culex) fuscocephala Theobald. (Cx.F), Culex (Culex) mimulus Edwards. (Cx.M), Culex(Culex) pseudovishnui Colless. (Cx.Ps), Culex(Culex) 
quinquefasciatus Say. (Cx.Q), Culex (Culex) vishnui Theobald (Cx.V), Culex(Eumelanomyia) pluvialis Barraud. (Cx.Pl), Culex (Culex) tritaeniorhynchus Giles (Cx.T) were recorded in the study area during the study periods.

Map 7 represents that association of population density with distribution of mosquito species in Yercaud villages. The distributed species are Aa.C, Aa.E, Aa.P, Aa.St, Aa.Su, Ae.V, Ae.Al, Ae.Ae, Cx.Ps, Cx.Q and Cx.V respectively.

Palaniyandi et al. [39,40-42] clearly demonstrate that, the web mapping GIS for customized embed mapping of disease prevalence, entomological parameters, sources of vector breeding habitats, epidemiological information, environmental and climate variables associated with dengue and chikungunya disease epidemics.

\section{Conclusion}

Climate, landscape and environments determinant variable play an important role and has influence on the epidemic transmission across the country. The application of GIS is potentially useful for stratification of transmission risk areas, and perhaps, useful for epidemic control and management in the country. Perhaps, the system would allow integration of data from any desktop, database, software or worksheet. It will facilitate updating of data from different nodes or centers. Nodal offices will be able to collate the data within no time. Mapping past and present situation of the mosquito surveillance will enable the administrative and the healthcare system to control the wildfire-like spread of these diseases. It could be used for converting the information between geographic geometric projection and the object information, and hyperlinks of spatial and non-spatial data. This technology could be essentially useful for the ongoing disease control operations and for decision making tool for taking appropriate measures for mosquito-borne disease epidemics control and management in future at the international level.

\section{References}

[1] Bhatt S, Gething PW, Brady OJ, Messina JP, Farlow AW, Moyes CL, Drake JM, Brownstein JS, Hoen AG, Sankoh O, Myers MF, George DB, Jaenisch T, Wint GR, 
Simmons CP, Scott TW, Farrar JJ, Hay SI (2013) The global distribution and burden of dengue. Nature 25:504-507.

[2] Chaudhuri M (2013) What can India do about dengue fever? BMJ 346:164.

[3] Rezza G (2014) Dengue and chikungunya: Long-distance spread and outbreaks in naive areas. Pathog Glob Health 108:349-355.

[4] Naresh Kumar A, Murugan K, Shobana K, Madhiyazhagan P, Nataraj T, Thomas Vincent C, Donald R. Barnard (2015b) Factors influencing the spatial distribution of Anopheles larvae in Coimbatore District, Tamil Nadu, India. Acta Tropica 152:121-130.

[5] Govindraj MR, Ganeshkumar S, Selvaraj M, MacklinRani L, Kumar P, Suganthi P, Sunis IP, Thenmozhi V, Tyagi BK (2011) Development of new methodologies using remote sensing and GIS Technique to control vector borne diseases for Sitheri Hills, Dharamapuri District, Tamilnadu. $12^{\text {th }}$ Esri India User Conference pp1-8.

[6] Vine MF, Degnan D, Hanchette C (1997) Geographic information systems: their use in environmental epidemiologic research. Environ Health Perspectives 105(6):598-605.

[7] Clarke KC, McLafferty SL Tempalski BJ (1996) On epidemiology and geographic information systems: a review and discussion of future directions. Emerging Infectious Diseases 2(2):85-92.

[8] Briggs DJ, Elliott P (1995) The use of geographical information systems in studies on environment and health. World Health Statistics Quarterly 48(2):85-94.

[9] Tanser FC, le Sueur D (2002) The application of geographical information systems to important public health problems in Africa. Int J Health Geographicsn 1:4-12.

[10] Linthicum KJ, Bailey CL, Davies FG, Tucker CJ (1987) Detection of rift valley fever viral activity in Kenya by satellite remote sensing imagery. Science 235:1656-1659.

[11] Pope KO, Sheffner EJ, Linthicum KJ, Bailey CL, Logan TM, Kasischke K, Birney ES Njogu AR, Roberts CR (1992) Identification of central Kenyan Rift Valley Fever virus vector habitats with Landsat TM and 1040. J med ent 40:185-196.

[12] Wood BL, Beck LR, Washino RK, Hibbard K, Salute JS (1992) Estimating high mosquitoproducing rice fields using spectral and spatial data. Int J Remote Sensing 13:2813-2826.

[13] Dale PE, Morris CD (1996) Culex annulirostris breeding sites in urban areas: using remote sensing and digital image analysis to develop a rapid predictor of potential breeding areas. $\mathbf{J}$ American Mosq Con Ass 12:316-320. 
[14] Thomson MC, Connor SJ, Milligan PJM, Flasse SP (1996) The ecology of malaria-as seen from Earth-observation satellites. Ann Trop Med Parasitol 90:243-264.

[15] Masuoka PM, Claborn DM, Andre RG, Nigro J, Gordon SW, Klein TA, Kim H (2003) Use of IKONOS and Landsat for malaria control in the Republic of Korea. Remote Sensing Environment 88:187-194.

[16] Zou L, Miller SN, Schmidtmann ET (2006) Mosquito larval habitat mapping using remote sensing and GIS: Implications of coalbed methane development and west Nile Virus. J Med Ent 43:1034-1041.

[17] Palaniyandi M, Mariappan T (2013) Master plan for mosquito control in the metropolitan cities in India using GIS. J Geospatial Today 12(8):28-30.

[18] Parmesan C (2006) Ecological and Evolutionary Responses to Recent Climate Change." Annual Review of Ecology, Evolution, and Systematics 37(1): 637-669.

[19] Daniel R. Cayan DR, Maurer EP, Dettinger MD, Tyree M, Hayhoe K (2008) Climate change scenarios for the California region. Climatic Change 87(0): 21-42.

[20] Bale JS, Masters GJ, Hodkinson ID, Awmack C, Bezemer TM, Brown VK, Butterfield J, BuseA, CoulsonJC,FarrarJ (2002) Herbivory in global climate change research: direct effects of rising temperature on insect herbivores. Glob Change Biol 8: 1-16.

[21] Nareshkumar A, Murugan K, Madhiyazhagan P, Nataraj T, Shobana K (2014) Impact of climate change on filarial vector, Culex quinquefasciatus and control using bacterial pesticide, spinosad. Asian Pac J Trop Dis 4(1):S87-S91.

[22] Denlinger DL, Yocum GD (1998) Physiology of heat sensitivity. In Temperature sensitivity in insects in integrated pest management. Edited by Hallman GJ, Denlinger DL. Westview Press Boulder pp7-57.

[23] Hardy JL, Houk EJ, Kramer LD, Reeves WC (1983) Intrinsic factors affecting vector competence of mosquitoes for arboviruses. Annu Rev Entomol 28:229-262.

[24] Chamberlain RW, Sudia WD (1955) The effects of temperature on the extrinsic incubation of eastern equine encephalitis in mosquitoes. Am J Hyg 62:295-305.

[25] Strickman D, Kittayapong P (2003) Dengue and its vectors in Thailand: calculated transmission risk from total pupal counts of Aedes aegypti and association of wing-length measurements with aspects of the larval habitat. Am J Trop Med Hyg 68: 209-217. 
[26] Wilson JJ, Sevarkodiyone SP (2014) Breeding preference ratio of dengue and chikungunya vectors in certain rural villages of virudhunagar district, Tamil Nadu, South India. World Appl Sci J 30:787-791.

[27] Rajesh K, Dhanasekaran D, Tyagi BK (2013) Survey of container breeding mosquito larvae (Dengue vector) in Tiruchirappalli district, Tamil Nadu, India. J Entomol Zool Stud 1:88-91.

[28] Wada Y, Mogi M (1974) Efficiency of the dipper in collecting immature stages of Culex tritaemorhynchus sumorosus. Trop Med 16:35-40.

[29] Shogaki Y, Makiya K (1970) An improved device for quantitative sampling of mosquito larvae. Jpn J Sanit Zool 21:172-178.

[30] Lawler SP, Lanzaro GC (2005) Managing Mosquitoes on the Farm. ANR Publication 8158, ISBN 978-1-60107-327-3.

[31] Barbara Matthys, Eliézer K. N’Goran, Moussa Koné, Benjamin G. Koudou, Penelope Vounatsou, Guéladio Cissé, Andres B. Tschannen, Marcel Tanner, Jürg Utzinger (2006) Urban agricultural land use and characterization of mosquito larval habitats in a medium sized town of Côte d'Ivoire. Journal of Vector Ecology 31:(2)319-333.

[32] Naresh Kumar A, Murugan K, Thomas Vincent C, Madhiyazhagan P, Nataraj T, Shobana K (2015a) The distribution of Culex mosquitoes in Coimbatore, Tamil Nadu, India. Journal of Entomological and Acarological Research volume 44(4565):1-15.

[33] Smallegange RC, Takken W (2010) Host-seeking behaviour of mosquitoes responses to olfactory stimuli in the laboratory. In Olfaction in Vector-Host Interactions (Takken, W. and Knols, B.G.J., eds), Wageningen Academic Publishers pp143-180.

[34] Braks MAH, Meijerink J, Takken W (2001) The response of the malaria mosquito, Anopheles gambiae, to two components of human sweat, ammonia and L-lactic acid, in an olfactometer. Physiol Entomol 26:142-148.

[35] Gilbert IH, Gouck HK, Smith N (1966) Attractiveness of men and women to Aedes aegypti and relative protection time obtained with DEET. Fla Entomol 49:53-66.

[36] Qiu YT, Smallegange RC, van Loon JJA, Ter Braak CJF, Takken W (2006) Interindividual variation in the attractiveness of human odours to the malaria mosquito Anopheles gambiae s. s. Med Vet Entomol 20:280-287. 
[37] Sharma SK, Jalees S, Kumar K, Rahman SJ (1993) Knowledge, attitude and beliefs about malaria in a tribal area of Bastar district (Madhya Pradesh). Indian J Public Health 37(4):129-132.

[38] Pravin NY, Keerti SJ, Mohini J (2013) A Study on Awareness and Practice about Preventive Methods against Mosquito Bite among Households in an Urban Slum Area of South India. International Journal of Recent Trends in Science and Technology 8(2):69-71.

[39] Palaniyandi M (2012) The role of Remote Sensing and GIS for Spatial Prediction of Vector Borne Disease Transmission - A systematic review. J Vector Borne Dis 49(4):197-204.

[40] Palaniyandi M (2013a) GIS for epidemic control in India. Geospatial World Weekly 9(28):1-4.

[41] Palaniyandi M (2013b) mapping of vector breeding habitats. Geospatial World Weekly 9(2):1-4.

[42] Palaniyandi M (2013c) Remote Sensing and GIS for mapping the geographical distributions and the ecological aspects of vector borne diseases in India: review article. J GIS India 22(1):4-7. 
Table 1 Number of immature mosquitoes recorded in the Yercaud revenue villages

\begin{tabular}{|l|l|c|}
\hline \multicolumn{1}{|c|}{ S. No. } & \multicolumn{1}{|c|}{ Name of the place } & Number of larvae/dip \\
\hline $\mathbf{1}$ & Yercaud & $2.0 \pm 0.30$ \\
\hline $\mathbf{2}$ & Muluvi & $5.1 \pm 0.91$ \\
\hline $\mathbf{3}$ & Kombu Thukki & $5.8 \pm 1.23$ \\
\hline $\mathbf{4}$ & Nagalur & $5.1 \pm 0.45$ \\
\hline $\mathbf{5}$ & Manjakuttai & $5.5 \pm 1.54$ \\
\hline $\mathbf{6}$ & Asambur & $4.8 \pm 0.80$ \\
\hline $\mathbf{7}$ & Kiliyur & $2.1 \pm 0.91$ \\
\hline $\mathbf{8}$ & Sengadu & $4.3 \pm 1.95$ \\
\hline $\mathbf{9}$ & Gundur & $5.6 \pm 1.11$ \\
\hline
\end{tabular}




\section{Figures}

\section{MAP 1: Toposheet of the study area (Yergaud taluk, Salem, Tamil Nadu, India)}

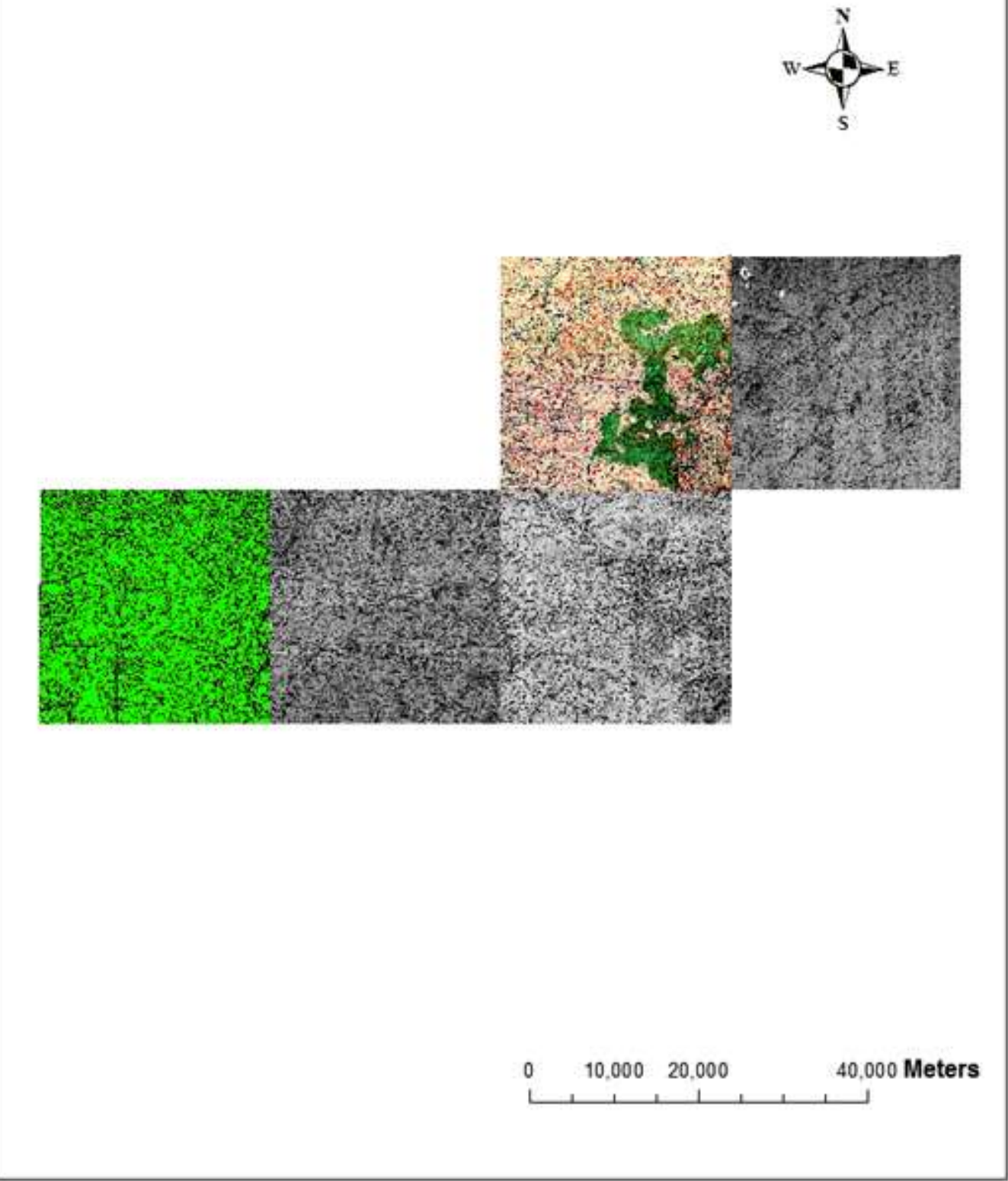




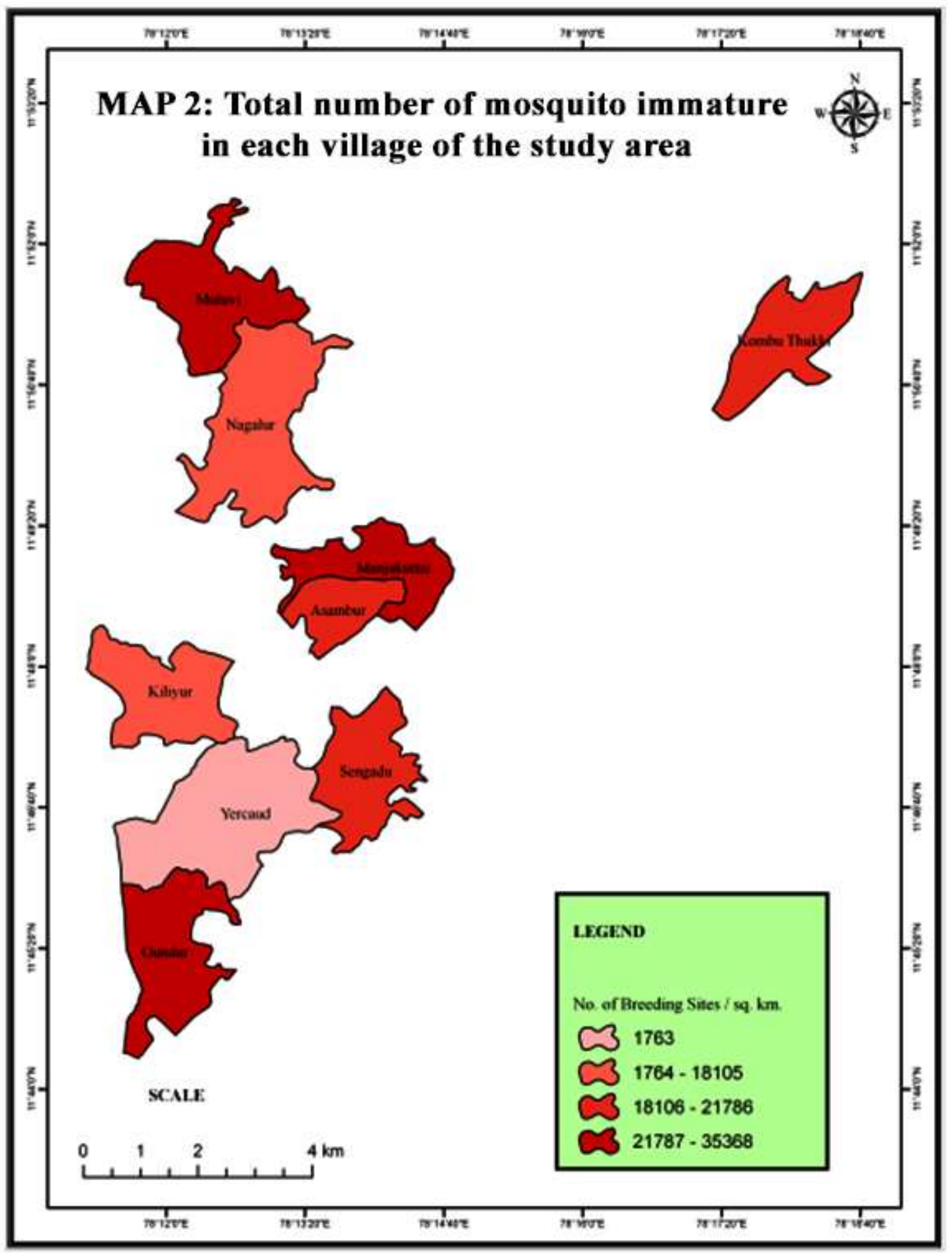




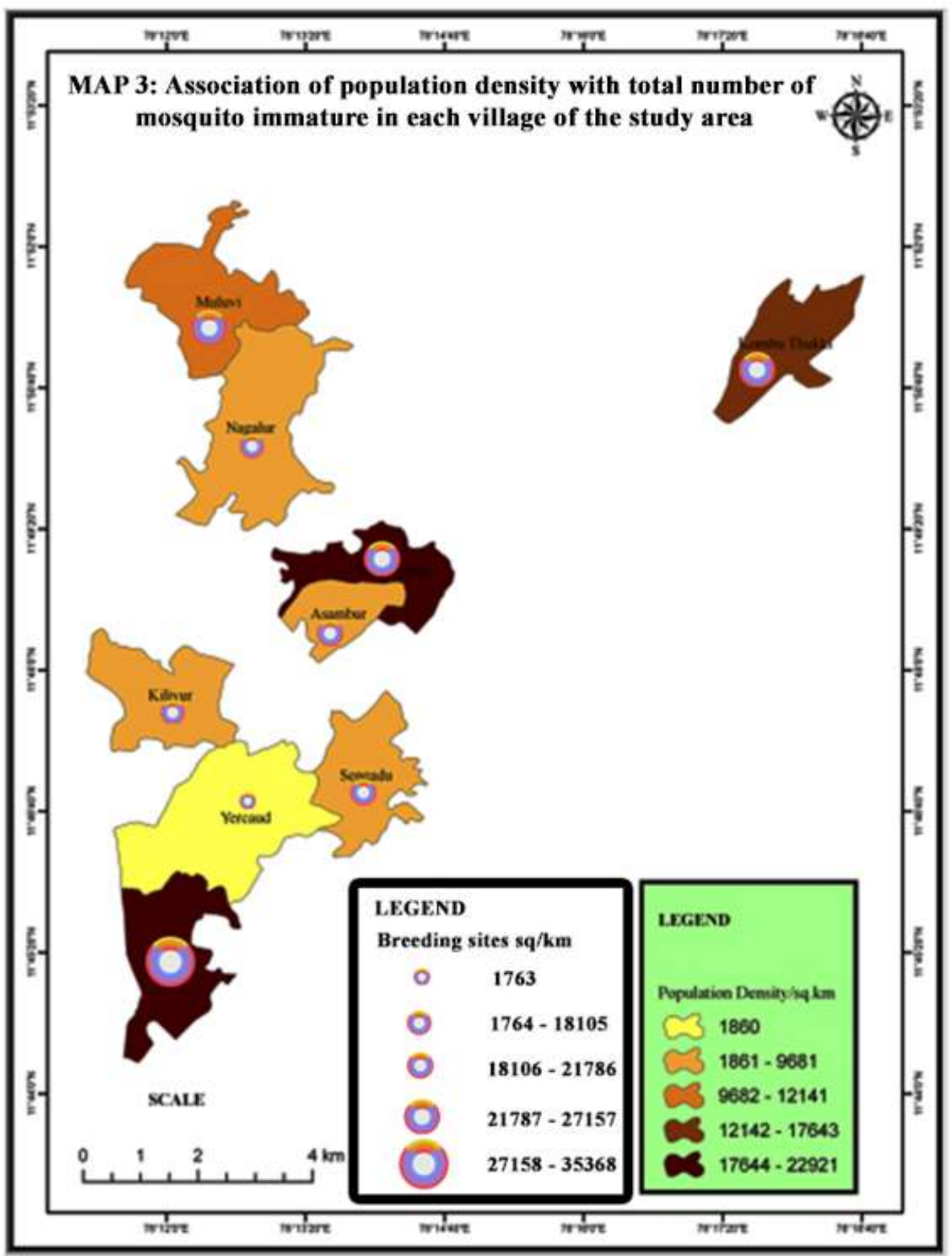




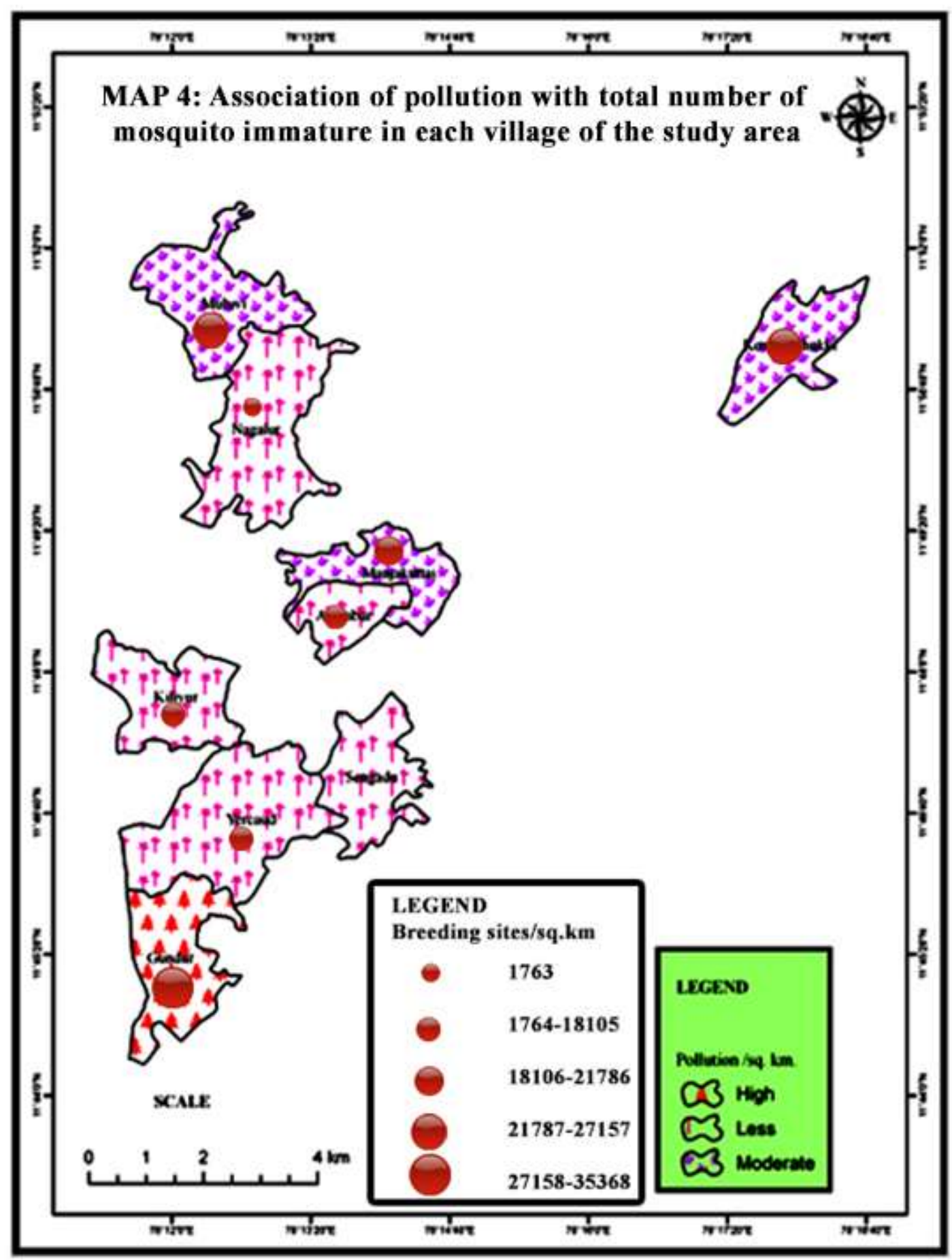




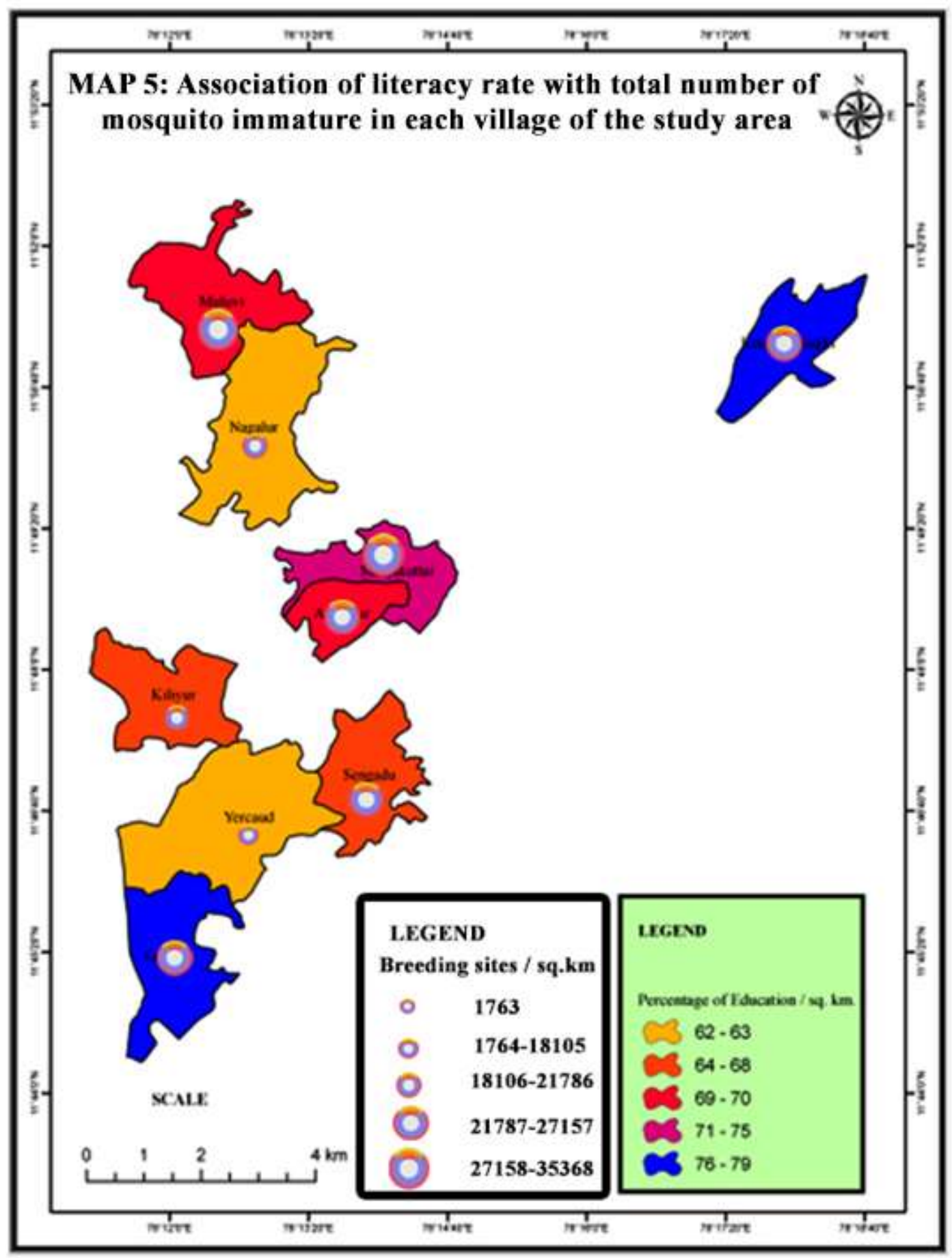




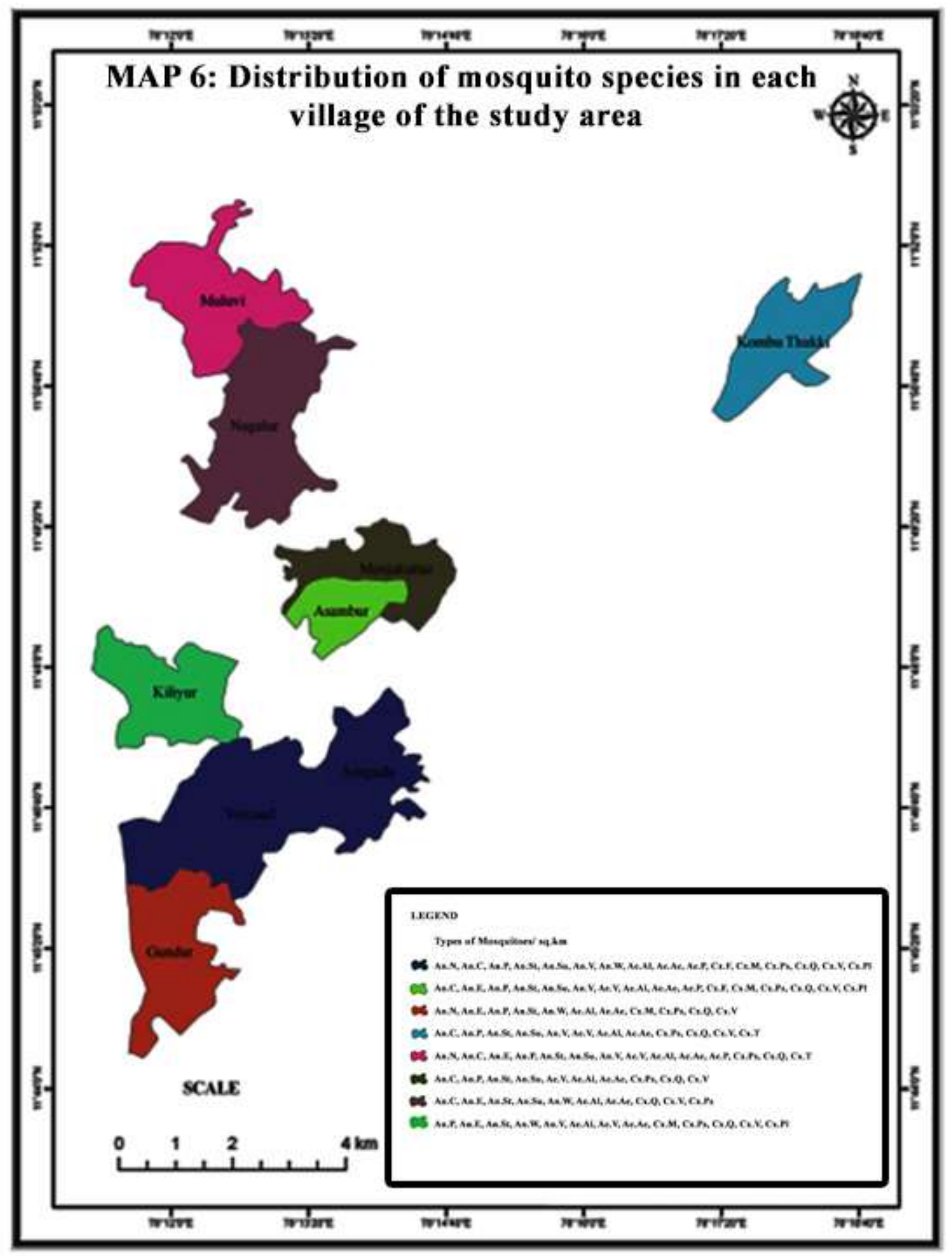




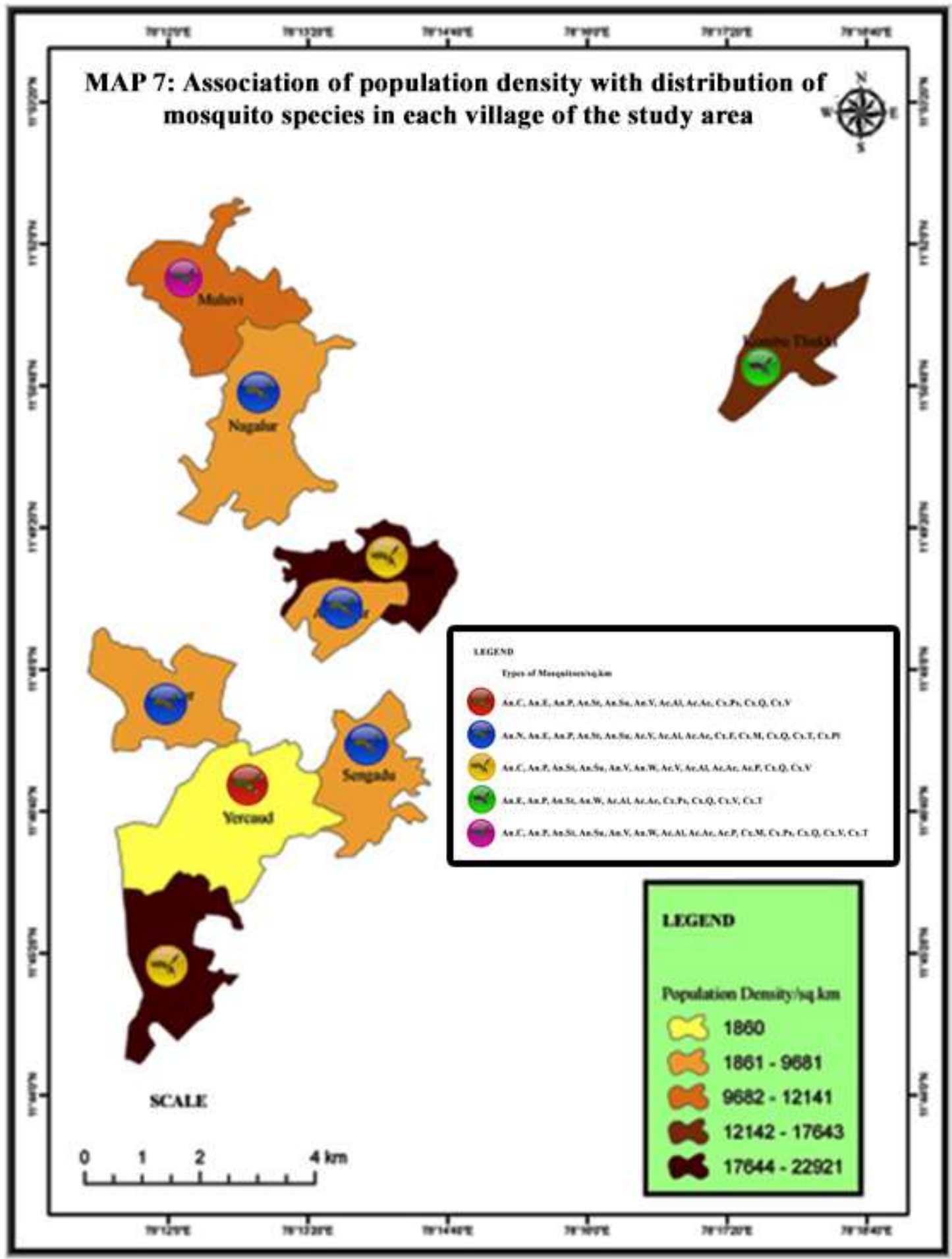

